\title{
THIRD-GENERATION SYPHILIS AND BILATERAL INTERSTITIAL KERATITIS OCCURRING IN ALL THE SURVIVING MEMBERS OF TWO GENERATIONS*
}

\author{
BY \\ F. S. BONUGLI \\ Royal Victoria Hospital, Belfast
}

Physicians who have the opportunity of studying the results of a syphilitic infection on family units as well as on individuals must, on occasion, be forced to inquire how often and how seriously is third generation lues sought out, and whether third generation disease is as rare as is generally supposed.

During the last 3 years I have encountered several cases of syphilis which I feel cannot be explained on other than a third-generation basis.

Two of these patients have a mother who at the age of 10 years had bilateral interstitial keratitis, which has left typical scars obvious to the naked eye, and who is now sero-fast in spite of adequate treatment a few years ago. These young adults -aged 14 and 16 years-have both clinical and radiological evidence of periostitis of the tibial bones, their serological tests are negative as far as Wassermann reaction, Kahn, and Sigma are concerned, their cerebrospinal fluids are also normal in all respects, and, although they now show only doubtful signs of syphilis, they were both treated for lues some years ago by a physician in a provincial hospital. The only records now obtainable are unfortunately somewhat lacking as far as diagnostic criteria are concerned, but both patients apparently had at least one set of positive serum Wassermann reactions and serum precipitation tests before the institution of treatment.

In another case completion of the criteria would have involved the examination of a maternal uncle, so far not accessible, who had had an inflamed tibial bone as a child, according to the patient's mother.

The results of examinations (Fig. 1) carried out on two generations of a third family in which two children were affected are here reported in the order in which their cases were reviewed.

\footnotetext{
* Received for publication October 14, 1953
}

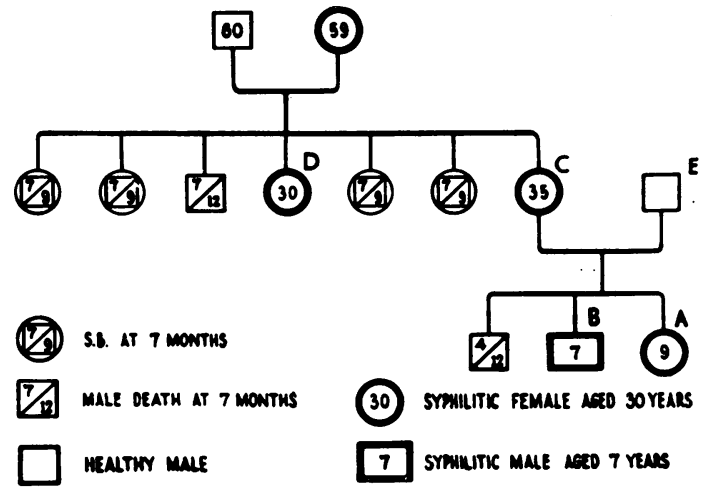

FIG. 1.-Family tree.

Case Reports

May, 1950-Case "A ".-A well-nourished female child aged 7 years, who had already been diagnosed as suffering from lues by a physician and ophthalmologist, was referred for further investigation and management.

Examination.-She had a typical active interstitial keratitis of the left eye of 6 weeks' duration ; the right cornea was normal, but the pupil was dilated and showed no reaction to light (this eye which was not atropinized at this time also became involved in a keratitic process 4 weeks later). The upper central incisors were Hutchinsonian in type and a suggestive facies was noted, but no other physical signs were found. The results of the laboratory investigations are given in the Table.

The past medical history of this child revealed that, apart from surgical intervention for anal fissure, she had always enjoyed excellent health. The mother at this stage refused to accept either the diagnosis or its domestic implications, on the grounds that she had never placed herself in a position where she could have contracted "such a disease", and she was certain that this held true for her husband also. Her husband, 
younger child, and herself were and always had been in excellent health. She was unable to accept the possibility of a non-venereal or asymptomatic infection -a possibility which was sympathetically presented to her on many occasions during the period this child was attending for treatment.

November, 1952-Case " B".-The younger brother of Case " A", aged 7 years was referred by his family doctor as the mother was anxious because the boy had been rubbing his right eye for about a week and she thought she had been able to see something in the clear part of his eye for the past 7 days. The boy stated that his eye had been itchy for several weeks, but was not sore.

Examination.-A very slight corneal haze was appreciable when the eye was examined in a good light without the aid of a lens. A rather less degree of corneal haze was also seen in the left eye. The right eye exhibited ciliary congestion. The facies of the child was slightly suggestive and the upper central incisors " screw-driver" in type, but detailed clinical examination revealed no other physical signs. The results of laboratory investigations are given in the Table.

Past medical history revealed that the child had suffered from whooping cough, measles, and chicken-pox but had otherwise enjoyed good health.

November, 1952-Case " C",.-The mother of Cases " A" and " B", aged 35 years, now submitted herself without protest to medical review but first desired to ask why such an interest was being taken in her children's teeth? On being told that the teeth were sometimes informative about the health of individuals in early infancy, she recalled that her own upper central incisors had been very small. Further questioning revealed that one upper incisor had been removed at the age of 14 because of premature decay, and that the other had been broken earlier in life. Subsequently, on being presented with several photographs of incisor abnormalities specific and otherwise, she rejected the suggestion that her incisor teeth had been like any shown in the photographs, but, on being shown a simple drawing of a normal upper incisor and an upper central incisor with the somewhat exaggerated notch at its incisional edge, her eyes lit up as she pointed to the latter drawing. She then added that 11 years earlier she too had had a scum over parts of both corneae which impaired her visual acuity for several months. She was at that time referred by her doctor-now deceased - to an ophthalmic hospital, where, after a local examination, she was handed over to a nurse to have a sample of blood taken from her arm; the nurse, however, was unsuccessful in the task allotted to her. Later she was apparently seen by a physician at the same hospital and examined all over, much interest being taken in her dietary history, which revealed that she had never eaten butter in her life. No further attempts to get blood from her arm were made. She was given drops for her eyes and advised to take large doses of cod-liver oil. No injection treatment was offered, and her eye condition eventually resolved after about 12 weeks.*

The patient then advised me that her only surviving sister had also had eye trouble a quarter of a century ago, for which blue ointment rubs and injections had been prescribed. On being asked if she had any anxieties about herself at the moment, her reply was that she could only complain of feeling easily tired; this had been present only for a few months. The results of laboratory investigations are given in the Table.

\footnotetext{
* Requests for case notes to the hospital concerned revealed that all records more than 10 years old, except for patients still attending,
} had been destroyed.

\begin{tabular}{|c|c|c|c|c|c|c|c|c|c|}
\hline \multicolumn{6}{|c|}{ Patient } & \multirow{2}{*}{$\frac{\text { Mother (C) }}{\text { November, } 1952}$} & \multirow{2}{*}{$\frac{\text { Aunt (D) }}{\text { November, } 1952}$} & \multirow{2}{*}{$\begin{array}{c}\text { Daughter (A) } \\
\text { June, } 1950\end{array}$} & \multirow{2}{*}{$\frac{\text { Son (B) }}{\text { November, } 1952}$} \\
\hline Date of & Exami & nation & $\cdots$ & $\cdots$ & $\cdots$ & & & & \\
\hline Signs & $\cdots$ & $\cdots$ & $\cdots$ & $\cdots$ & $\cdots$ & Nil & $\begin{array}{c}\text { Hutchinson's incisors } \\
\text { and Sabre tibia }\end{array}$ & Bilateral keratitis & Bilateral keratitis \\
\hline History & $\cdots$ & $\cdots$ & $\cdots$ & $\cdots$ & $\cdots$ & $\begin{array}{c}\text { Hutchinson's incisors } \\
\text { and keratitis, } 1941\end{array}$ & Keratitis, 1928 & 一 & - \\
\hline \multirow{3}{*}{\multicolumn{3}{|c|}{ Serum }} & \multicolumn{3}{|c|}{ Sigma } & $326 \cdot 2$ & 0 & $217 \cdot 4$ & $108 \cdot 7$ \\
\hline & & & \multicolumn{3}{|c|}{ Wassermann reaction } & $+\overline{+}$ & -- & ++ & ++ \\
\hline & & & \multicolumn{3}{|c|}{ Kahn test } & +++ & -- & +++ & - + \\
\hline \multirow{6}{*}{\multicolumn{3}{|c|}{ Cerebrospinal Fluid }} & \multicolumn{3}{|c|}{ Leucocytes } & 100 & 2 & 8 & 2 \\
\hline & & & \multicolumn{3}{|c|}{ Red blood corpuscles } & - & 21 & 0 & 4 \\
\hline & & & \multicolumn{3}{|c|}{ Protein (mg. $\%)$} & 55 & 35 & 30 & 35 \\
\hline & & & \multicolumn{3}{|c|}{ Globulin } & Trace & Nil & Trace & Trace \\
\hline & & & \multicolumn{3}{|c|}{ Wassermann reaction } & $+\dot{+}+$ & Negative & ++ & \pm- \\
\hline & & & \multicolumn{3}{|c|}{ Lange } & 5432100000 & 0000000000 & 0111100000 & 0000000000 \\
\hline
\end{tabular}


Her past medical history was otherwise negative for anything suggestive of lues. Apart from a very slight tendency for one pupil to be ovoid in shape and a fairly marked degree of genu valgum, no abnormal physical signs were found. The corneae were clear to the naked eye and lens examination ; her upper incisor teeth were absent and the lower ones normal.

Her third child - a boy - had died of jaundice at the age of 4 months, and she had had no miscarriages or still-births.

December, 1952-Case "D". - The sister of Case " C", and aunt of Cases "A" and "B", aged 30 years, had a past medical history of bilateral keratitis for which she was given injections and blue ointment rubs as a young child. She produced from her handbag the prescription given to her mother in 1928 to purchase drugs for her rubs and therapy; this prescription was for sulpharsphenamine and blue ointment (Fig. 2).

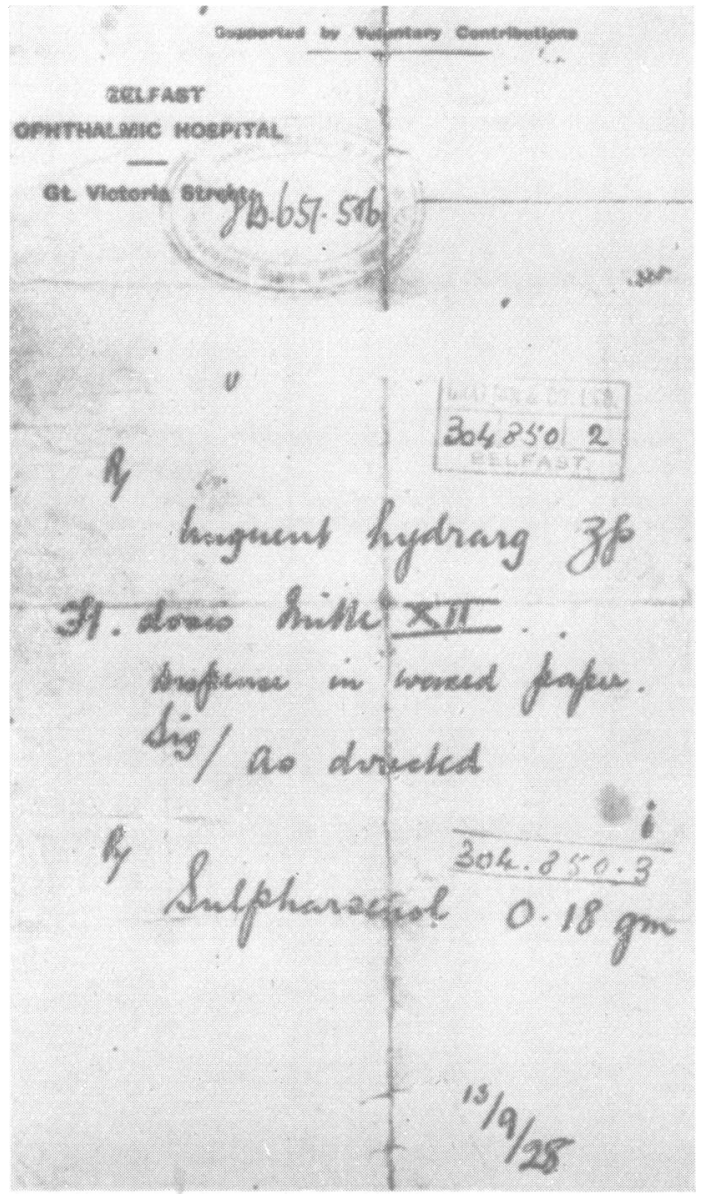

FIG. 2.-Prescription given to Case "D" 25 years ago.

On examination, she had an open bite, and typical upper central Hutchinsonian incisors, and the lower incisors were also small, thickened, notched, and not free from suspicion, Her tibial bones showed marked thickening and the vibration sense over the sacrum was absent, but no other physical signs were discovered. The results of laboratory investigations are given in the Table.

January, 1953-Case "E".-The husband of Case " $C$ " and father of Cases " $A$ " and " $B$ ", aged 36, on complete examination showed no historical, clinical, or serological signs of syphilis ; an earlier Wassermann reaction and Kahn test in May, 1950, had been negative.

\section{Discussion}

No one will dispute the syphilitic status of Cases "A", "B", "C", and "D", whose serological tests are still positive 6 months to 2 years after diagnosis, nor will any question be raised about the diagnosis of a prenatal infection in Cases " $A$ ", "B", and "D", where the infection in each of these cases is easily placed chronologically by the existence of typical dental anomalies to the very late days of gestation or the early months of extrauterine life. Even, however, in the absence of these dental anomalies, it is submitted that bilateral interstitial keratitis occurring in two members of the same family at such tender years associated with the other clinical and serological findings in these cases and their immediate relatives would be adequate evidence in itself of a prenatal infection in both children.

A more serious objection could be raised to the lack of objective evidence of a congenital infection in Case " $\mathrm{C}$ ", but it must be conceded that the spontaneous description given of isolated dwarfism of the upper central incisors associated with incisional notching cannot be dismissed or explained away easily, as particular care was taken to avoid suggesting the answers to this woman. Some difficulty too in finding alternative causes for this woman's impaired vision 11 years earlier is also experienced ; it is suggested that the ophthalmologist actually had syphilis in mind when he referred this case for blood testing and for the opinion of a general physician, and it is suggested that the diagnosis at that time was missed by the parties concerned. The possibility of the mother's eye complaint being explicable on the grounds of a vitamin deficiency due to a defective diet must of course be considered, but this would be difficult to substantiate even if one only took into consideration her dietary habits, as the aversion she had was to butter only and not to the other fat-soluble vitamincontaining foods which were apparently consumed in adequate amounts.

Ophthalmologists may regard as regrettable the 
absence of slit-lamp microscopy findings in the mother, but it has not been possible to make this examination. I would not, however, be prepared to accept the absence of microscopic scarring as necessarily evidence against a past history of syphilitic keratitis. My experience in at least two other cases leads me to question the text-book teaching in this respect. Objection may also be taken to the fact that the grandparents have not been examined. Unfortunately, the grandfather became aware of the diagnosis given to explain the illness of his grandchild before the more interesting details of these cases were known; he refused his cooperation and would not permit the grandmother to relieve the mother in fetching the children for treatment as I hoped might be arranged. This omission is counteracted by the positive clinical picture presented by the children's aunt (Case " D"), who for the benefit of the cynic bears a close physical resemblance to her sister and her sister's children. The grandmother's obstetric history (Fig. 1) was obtained for me by the children's mother, Case " $\mathrm{C}$ ".

\section{Conclusion}

In the investigations of these and other cases it has repeatedly occurred to me that the incidence of third generation syphilis is probably underestimated. Some factors which play a role in concealment of the incidence are considered to be :

(a) complete medical investigation of three generations in a subject still so emotionally charged as syphilis is particularly difficult.

(b) successful completion of investigations of this type are unlikely except in areas of fixed population.

(c) the most productive areas today are likely to be those remote from physicians having a special interest in the subject.

(d) the difficulty of getting across to interested parties any non-venereal aspects of syphilis. (e) the possibility of default interfering with an investigation of this type is greater where one has to depend on a group of people.

$(f)$ those anxious to look for third-generation disease must be prepared epidemiologically to investigate all their cases of syphilis and only rarely hope to be able to publish a case sufficiently documented to be acceptable.

$(g)$ earlier coincidental or carefully planned treatment will in many cases permanently obliterate physical signs from a case which might have turned out later to be the essential link in the chain of evidence. For obvious reasons the possibility of this happening now is increasing.

(h) many cases of prenatal syphilis have no physical signs indicative of a congenital infection, and if these cases are diagnosed for the first time in adult life they are unlikely to be recognised as such unless they fall into the hands of physicians interested in applying the epidemiological principles which alone provide the evidence of origin of the infection in these cases.

(i) the general reluctance of the medical profession and others to initiate, encourage, or take part in an investigation of a type which appears superficially to be hazardous to family unity.

\section{Summary}

A detailed description is given of two cases of third-generation syphilis occurring in the same family. The coincidental findings of interstitial keratitis in all the surviving members of two generations of this family is also noted. Finally, the typical slow insidious evolution of luetic manifestations extending over a quarter of a century in a hitherto " unmanaged" family group is described.

My thanks are due to Dr. Eric Bolton for permitting me to investigate and treat this interesting family, to Mr. D. H. R. Mehaffey for the photographic reproductions, to Mr. G. A. Smith, medical artist, and Sister Jean Fox, of the Royal Victoria Hospital, for their help. 